\title{
Instructional Teaching Design and Analysis of Word Advanced application in Applied Undergraduate Colleges
}

\author{
Nan Xie ${ }^{1, a^{*}}$ and Liru Han ${ }^{1, b}$ \\ 'Zhejiang University of Water Resources and Electric Power, Hangzhou, China \\ a905321899@qq.com, b0521449018@qq.com \\ * The Corresponding Author
}

Keywords: Word advanced application; Applied undergraduate; Mail merger; General education

\begin{abstract}
Word advanced application, as an organic part of Applied Undergraduate non computer major general knowledge course -- office software advanced application course, is of great significance to improve student Word office software application level. Therefore, based on the importance of teaching design, the mail merge function of Word in the advanced application has been focused, and it detailed analysis of the teaching ideas and the teaching steps has been put forward in order to know the teaching quality of computer application for applied undergraduate colleges, and provide the teaching of practical reference value and guiding significance. It is also to improve the teaching effect of the related courses, and to provide some teaching ideas for the improvement of the application type and the training of comprehensive talents.
\end{abstract}

\section{Introduction}

As an important component of MS-Office software, MS-Word is also an important tool to process document using office software. Flexible use of it can greatly improve people's daily office efficiency. At present, all applied undergraduate colleges and universities have set up related computer application foundation courses related to computer application and office software, aiming at training students' computer application ability. In the teaching of computer application basic course in application-oriented universities, how to correctly apply relevant teaching cases and scientifically design teaching contents will directly affect the learning efficiency of students. A reasonable teaching design emphasizes that teachers should fully respect students' main position in teaching process, and actively guides students to explore independently, so as to successfully complete teaching tasks. This paper selects an important section of the MS-Office Word advanced application, and takes Word as an example to explain the teaching design of the related courses [1].

\section{Importance of Teaching Design}

Teaching design is mainly based on teaching standards and characteristics of teaching objects, arranging various teaching elements in a rational and orderly way, and ultimately establishing a scientific teaching plan. Generally speaking, a complete set of teaching designs includes teaching objectives, teaching difficulties and teaching methods. The teaching of computer general courses for non-computer majors in applied undergraduate colleges is not only the understanding of basic knowledge of computers, but also the interpretation of new technologies and developments in computer development, and the flexible use of computer operation skills and skills. Therefore, teachers need to carefully design the teaching content of each class. The teaching content design of senior office software application course, feature requires teachers to fully reference teaching syllabus, teaching objectives and teaching object, combined with the actual situation of applied undergraduate course characteristics and applied undergraduate colleges, using scientific teaching methods, optimization of the various elements in classroom teaching, in order to achieve the optimization of the teaching effect. The teaching design of the advanced application course of office software is beneficial to the teachers to organize the teaching activities according to the teaching goals [2-5]. Therefore, instructional design 
can follow the basic rules of teaching process and choose teaching objectives rationally, and correctly solve the problem of teaching content selection. At the same time, teaching design is guided by the system method and systematizes all the problems that need to be solved, so as to achieve the optimization of teaching effect.

\section{Teaching Design of Mail Merge Function}

Word advanced application teaching focuses on operation practice and its application. In this paper, we take the knowledge of mail merge in Word advanced application to analyze and explain the specific implementation process of Word advanced application classroom teaching design [7-8]. In the process of teaching, the following aspects should be taken into consideration.

The Object of Course Teaching. The application oriented undergraduate education pays more attention to the application of teaching and tends to practice teaching, focusing on the education of the practical links of the students. At the same time, students in the application oriented universities have a higher level of career orientation. Because of their professional characteristics, they know their future direction, so teachers need to design different teaching cases according to their different professional characteristics. Students in applied undergraduate colleges have more autonomy in their learning process. Students can control their time freely and choose some suitable learning contents for their future employment development. Therefore, teaching methods such as case analysis and task driving in practical teaching are of great importance to improve students' learning efficiency and cultivate their practical application ability.

The Teaching Goal of the Course. Word software is one of the most widely used office text processing software. In the "Word advanced application" in the mail merge function refers to the fixed content mail document, combined with a number of related information and send data, these data can be derived from the Excel table, Access table and other data sources, so as to generate documents, greatly improve office efficiency. So its main teaching goal is to require students to master the application of mail merge function, understand the use of Word common fields, and master the operation of mail merge function related toolbar. The teaching difficulty is how to use templates to finish document printing of similar contents, or send them out by mail, and share all kinds of data sources, and use application sorting and sorting functions, so as to improve operator's office efficiency.

The Teaching Content of the Course. In people's daily work, it is often necessary to deal with a large number of letters, letters, and various report documents. Though documents are complex, these documents can be divided into two parts: fixed and variable parts, that is, most of them are basically the same content formats, and only need to change relevant data. As an important operation function of Word advanced application, mail merge can greatly improve the practical application ability of the students. According to the requirements of the syllabus, students should learn to apply and be familiar with the mail merge function. Meanwhile, in the process of teaching, in order to fully mobilize students' interest in learning, combined with the characteristics of applied undergraduate students, set up related learning tasks, so that students learn to grasp the mail merge function in the actual application process. In this way, students can not only improve their interest in learning, but also make the computer classroom teaching more in line with the actual needs.

The Design and Analysis of the Course Teaching Process. It is roughly divided into three links. The first link: review link, namely review of the basic knowledge of Word. Teachers guide students to review the basic knowledge of Word courses, such as toolbar operation, text processing, related table processing, and so on. At the same time, teachers use PPT or micro courses to introduce new teaching contents, and show the related emails edited by Word, thus introducing new topics. The second link: teaching of new knowledge and content in the classroom. There are two main operations in the process of mail merging: the design of the master document and the generation of the data source. Among them, the main document design mainly involves the common content in various letters or different report files. Data sources include names, names, and specific time information in different letters or report files. Mail merge process is mainly through the correspondence between the information in the main document and the recorded information generated in the data source, so as to form the final 
merged document [8-9]. The mail merge operation is divided into three steps: 1) making the main document: input fixed content and format; 2) preparing the data source: record data contains the title line; 3) the data source into the main document by mail merge function, complete the required documents, operation flow chart in Fig. 1.

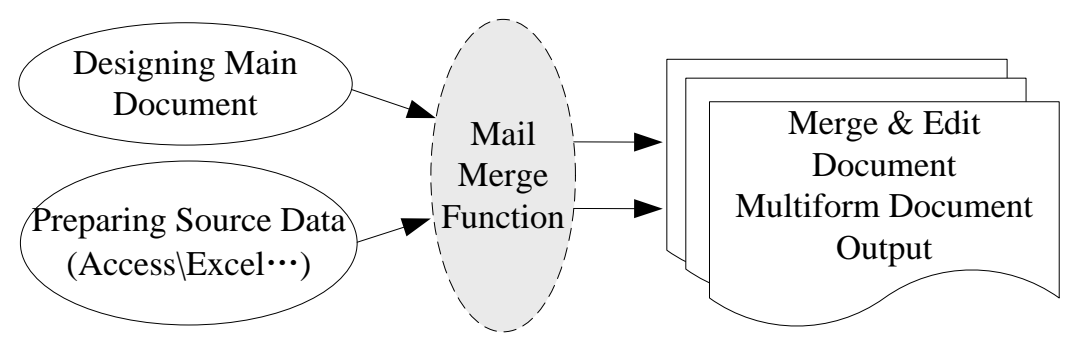

Figure 1. Finite Mail merge operation flow chart

The third link: the summary of the case operation in the classroom. First of all, class summarization, using mail merge function usually has two conditions: the number of transcripts, letters and other items that need to be produced is large, and the basic format and main content of document content will not change. In particular, the title, date and content of the document are fixed, while the specific objects of the merged document belong to the changing contents, which are recorded by data sources. Generally speaking, the "mail merge" function is mainly used in letters, invitations, payroll bars, and resume. As long as there are databases or spreadsheets and a standard two-dimensional data table, we can make use of the mail merge function in Word advanced applications to print in batches, thus greatly improving the work efficiency. Finally, after listening to the teacher's demonstration operation process, the students can think about and recall the three main steps of the mail merge operation, and arrange after-school assignments, such as the use of mail merge function to complete the A University $\mathrm{C}$ prize certificate production.

The Analysis and Thinking of Teaching Methods. 1) Case analysis. The teacher according to the actual situation of the students, analysis of teaching content, through the analysis of actual case, to enable students to achieve the combination of theory and practice, such as the process of teaching students the final exam transcripts, $\mathrm{C}$ prize winning certificate making, can better cultivate students' practical ability of operation. At the same time, the application of teaching cases close to the actual life of the students also helps to improve the students' enthusiasm and initiative in learning. 2) Task driven method. In the course of the teaching of task driven method, teachers need to analyze and design the task reasonably. In the design task, teachers must fully integrate the existing knowledge structure and knowledge level of the students in the applied undergraduate college. At the same time, teachers should evaluate students' task completion before the end of each class, and divide each case into several feasible tasks. For example, in this teaching process, each student can independently complete the main document design, the data source creation, and the mail merge process. In the process of completing the task, students find and raise questions, so as to deepen the understanding of relevant theoretical knowledge. In addition, the amount of extracurricular exercises is conducive to the students in the class to further consolidate and improve, in order to achieve the purpose of reliability, analogy. Therefore, task driven teaching method is a scientific teaching method. 3) The teaching method of micro class. With the vigorous development of computer Internet plus ", and the mutual penetration of information technology and traditional various disciplines and cross use more closely, the computer application course facing the hitherto unknown challenge, especially the micro teaching mode gradually penetrated into the various disciplines teaching in Universities Based on, has important significance for the innovation of school teaching method. Therefore, we can apply the micro teaching method to the office software advanced application teaching, and also improve the efficiency of classroom teaching and teaching effect.

The Effect of Teaching and the Assessment of the Course. Through the analysis of teachers' teaching effect and students' questionnaire survey for 2 years, for Application-oriented College Computer Courses in general education, analysis of teaching design for different professional design 
different teaching cases, which can greatly improve the students' learning interest and initiative, can effectively improve the quality of classroom teaching. In addition, in order to further promote our school "curriculum reform project", to promote the reform of classroom teaching ability as the standard, to promote the skills of both soft and hard training, classroom assessment can adopt the "knowledge + skill + attitude" three-in-one course assessment methods, better to improve the effect of classroom teaching.

\section{Conclusions}

Word is the advanced application of Applied Undergraduate Colleges - an important part of general education courses, senior office software application course of computer professional, in this paper, the teaching design good courses that directly affects the quality of teaching and learning efficiency of students and teachers. Therefore, in the "Internet plus" era, in the actual teaching process of computer courses, between teachers and students should actively cooperate to complete teaching tasks in a timely manner, not only help students enhance their ability, and can be better to complete the curriculum teaching goal.

\section{Acknowledgements}

This work was supported by the first demonstration core curriculum construction project of 13-5 of Zhejiang University of Water Resources and Electric Power (Project No.44).

\section{References}

[1] Jian Ke, Liu Yuncheng,.. Reform and practice of university computer course teaching: taking city College of Dongguan University of Technology as an example [J]. Dongguan University of Technology, 2017 24(1): 120-124.

[2] Sun Min. Research on teaching content of University Computer Course Based on Computational Thinking in Applied Colleges and universities [J]. Journal of Higher Education, 2016 (21):60-61.

[3] Wang Yonggang. The application of micro class in the basic teaching of computer research [J]. Time Education, 2017 (7): 184.

[4] Ren Haiyan. The application of micro class in computer basic teaching [J]. Computer Knowledge and Technology, 2017 13(2): 139-140,145.

[5] Cai Youlan, Ning Jifeng. The application of micro class in the teaching of the basic course of computer application [J]. China Computer \& Communication, 2016, (1): 235-236.

[6] Tang Wenjie. Application of micro class in computer teaching [J]. Asia-Pacific Education, 2016, (9): 68-68.

[7] Wan Xiaoming. The analysis of the teaching design of "Word advanced application" course [J], Software Guide, 2014(11): 173-175.

[8] Fan Xinhua. Some problems that should be paid attention to in general education in the application type colleges and universities in the transition of Higher Education[J]. Western China Quality Education, 2017(1): 19-20.

[9] Bai Shibing. The discussion and practice of computer basic teaching in Applied Undergraduate Colleges under the background of general education [J]. Fu Jian Computer, 2016 (34):120. 